\title{
Grain size effects in rime judgment across literacy development in German
}

\author{
Alexandra M. A. Schmitterer ${ }^{1}$ and Sascha Schroeder ${ }^{2, *}$ (iD) \\ ${ }^{1}$ Leibniz Institute for Research and Information in Education, Frankfurt am Main and ${ }^{2}$ Max Planck Institute \\ for Human Development, Berlin \\ *Corresponding author. E-mail: sascha.schroeder@mpib-berlin.mpg.de
}

(Received 28 July 2017; revised 30 October 2018; accepted 31 October 2018)

\begin{abstract}
Phonological similarity effects are biases to judge words as phonologically similar (i.e., rhyming), even if they are not. First found in rime awareness tasks in preliterates, these biases have recently also been found in proficient adult readers. In this study, we evaluated underlying phonological processing in rime judgment longitudinally, across literacy development. To this end, we created a new rime judgment task (rime; i.e., $/ \mathrm{t} \cdot \mathbf{a r} \cdot \mathbf{l} / \mathrm{l}-/ \mathrm{z} \cdot \mathbf{a r} \cdot \mathbf{l} /$ ) with two distractor conditions that varied in size of phonological overlap (body; i.e.,

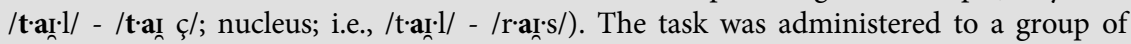
61 German-speaking children at four time points across school entry and to 21 adults. Accuracy and latency responses were recorded. Results indicated that children and adults showed phonological similarity effects but the effect decreased gradually over time. However, preliterate children were more sensitive to large compared to small phonological overlap, while the same effect was significantly smaller in literate children and adults. Results suggest that preliterate children are more sensitive to larger grain sizes and become more sensitive to fine-grained units across literacy development. The findings are in line with the assumptions of the psycholinguistic grain size theory.
\end{abstract}

Keywords: grain size; phonological similarity effects; rime judgment

Phonological awareness is an important predictor of reading abilities across languages (Caravolas, Lervåg, Defior, Malkóva, \& Hulme, 2013; Ziegler et al., 2010). Rime awareness is one of the underlying components of phonological awareness (Anthony \& Francis, 2005), and rime judgment tasks (e.g., flake-snake; "Are these words rhyming?") are one way to assess rime awareness. Some studies of children's rime judgment abilities have shown that preliterate children judge any type of phonological overlap as a rime (Cardoso-Martins, 1994). These biases to judge words as phonologically similar, even if they are not, are phonological similarity effects (i.e., Cardoso-Martins, 1994; Carroll \& Snowling, 2001). Phonological similarity effects were first understood as a sign for holistic phonological processing in preliterates. While some studies could show that this is true for global, phonetically 
based similarity biases, which strongly decrease across development (Carroll \& Myers, 2011), some recent studies report that phonological similarity effects can also be found in young readers and adults (Wagensveld, Segers, van Alphen, \& Verhoeven, 2013). It is, thus, unclear, whether these effects are caused by holistic phonological processing or not.

This article aims to study the underlying phonological processes in rime judgment to understand whether phonological similarity effects differ between preliterates and literates. To this end, a new rime judgment task with two distractor conditions was developed to study grain size effects during the phonological processing leading up to rime decisions. One distractor condition had the same size of phonological overlap as the rime (body) and one had a smaller size of overlap (nucleus). The task was administered to the same group of German-speaking children at four time points across the onset of reading instruction and, separately, to a group of adults.

\section{Development of phonological representations and reading acquisition}

The development of phonological representations is a development from bigger phonological units (e.g., syllable or rime) toward smaller phonological units (e.g., phoneme) and the ability to distinguish and manipulate different sizes of phonological units (Anthony \& Lonigan, 2004; Lonigan et al., 1998; Walley, 1993).

In the psycholinguistic grain size theory (Ziegler \& Goswami, 2005) it is argued that phoneme awareness is a necessary precondition for reading development, but the progression of phonological abilities and its relation to reading can differ between languages. In German, phoneme awareness develops only after children have acquired some orthographic knowledge, but children quickly adopt a phonemeby-phoneme decoding process once reading acquisition commences (Goswami, Ziegler, Dalton, \& Schneider, 2001; Goswami, Ziegler, \& Richardson, 2005).

In line with the assumption that phoneme awareness is important for reading development, phoneme awareness has been found to predict reading abilities in many languages (Caravolas et al., 2013), while rime awareness has not always been identified as an early predictor of reading abilities (see Castles \& Coltheart, 2004, for a review). At a first glance, thus, it seems beneficial to confine the assessment of phonological abilities with regard to the prediction of later literacy abilities to phoneme awareness assessments. However, Castles and Coltheart (2004) point out the difficulty of assessment of phoneme awareness abilities in children that due to factors in their language or educational environment have not yet developed phoneme awareness adequately (Castles \& Coltheart, 2004; Metsala \& Walley, 1998; Ziegler \& Goswami, 2005). Thus, the language and educational environment (i.e., training of phoneme-grapheme conversion, orthographic knowledge, and language structure) should be considered with regard to the study of phonological development and its connection to literacy development.

\section{Rime awareness and reading acquisition in German}

In German, for which studies show that neither phoneme awareness nor letter knowledge is usually strongly developed before school entry (Goswami et al., 2005; Mann \& Wimmer, 2002), the study of the development of rime awareness 
abilities and its connection to literacy development is an important step for the thorough understanding of the role of phonological awareness in literacy development. Further, in German, where children receive little literacy stimulation before school entry (Kuger, Rossbach, \& Weinert, 2013), rime awareness has been identified as a kindergarten predictor of later reading abilities multiple times (Ennemoser, Marx, Weber, \& Schneider, 2012; Näslund \& Schneider, 1996; Wimmer, Landerl, \& Schneider, 1994), and similar effects have previously been reported for other languages as well (Goswami, 1999; Goswami \& Bryant, 1990). After all, children with no phoneme awareness but good rime awareness are likely to be the first to proceed to the next level of phoneme sensitivity. Thus, how rime awareness and its underlying phonological processes are connected to literacy development remains a relevant topic to discuss.

\section{Phonological similarity effects in rime judgment}

Rime awareness is assessed with rime oddity (e.g., Bradley \& Bryant, 1978; De Cara \& Goswami, 2003) or rime judgment tasks (e.g., Cardoso-Martins, 1994; see Macmillan, 2002, for a review). Cardoso-Martins (1994) conducted a study in which preschoolers, kindergartners, and first graders had to decide, which of two words (i.e., bala or fogo) was rhyming with a target word (i.e., sala) and found that children had difficulties solving this task if distractors overlapped phonologically with the target (i.e., massa - laca vs. massa - passa). This bias to judge phonologically similar distractors as rhyming was specifically strong in preliterate children and decreased with increasing literacy skills. Results were replicated by Carroll and Snowling with 3- and 4-year-olds (2001) and by Wagensveld, van Alphen, Segers, and Verhoeven (2012) with Dutch-speaking 6-year-olds. In these studies, phonological similarity effects were viewed as evidence for preliterates' holistic processing of phonological information (Cardoso-Martins, 1994; Carroll \& Snowling, 2001), while literate children had developed analytical phonological processing strategies (CardosoMartins, 1994).

To some extent, these assumptions correspond with the psycholinguistic grain size theory (Ziegler \& Goswami, 2005). For example, both clusters of hypotheses postulate the progression from a broad perception to a fine perception of phonological units (holistic > analytical; coarse-grained $>$ fine-grained), and both share the belief that reading acquisition determines or at least advances this progression. Thus, it would be expected that throughout literacy development, the underlying phonological processing abilities that lead to a decision about phonological overlap in rime judgment are affected by the progression from an awareness of large grain sizes to an awareness of small and large grain sizes. This, however, has not been studied so far.

In contrast to these results and theoretical assumptions, some recent studies found phonological similarity biases in preliterates, beginning literates, and adults (Wagensveld et al., 2012, 2013). The authors concluded that phonological similarity effects are not markers of coarse-grained phonological processing in emergent literacy but based on a more fundamental and innate phonological processing capacity, which makes individuals sensitive to phonological overlap. While this 
might be true and is an important finding on phonological sensitivity in similarity judgments, the conclusion that underlying phonological processing abilities do not evolve throughout literacy development seems to be rather strong. Given the universal involvement of phonological abilities in literacy development (McBrideChang \& Kail, 2002; McBride-Chang \& Suk-Ho, 2005; Ziegler et al., 2010), it is rather unlikely that rime judgment is not affected by literacy development.

\section{Limitations of previous studies}

There are several methodological aspects of the previous studies that have to be discussed. First, while the effects reported by Carroll and Snowling (2001) were found in a longitudinal study, both Cardoso-Martins (1994) and the studies of Wagensveld et al. $(2012,2013)$ had a cross-sectional design. Changes of effects in rime judgment tasks might be easier to detect using designs that focus on changes that occur within individuals.

Second, previous studies did not control for phonological neighborhood density (e.g., Luce \& Pisoni, 1998; Marian, Bartolotti, Chabal, \& Shook, 2012). According to the lexical restructuring model (Metsala \& Walley, 1998), which was partly adopted in the psycholinguistic grain size theory (Carroll \& Myers, 2011; Ziegler \& Goswami, 2005), children are likely to develop fine-grained phonological representations earlier for words from dense phonological neighborhoods. Thus, in previous studies, stimuli material might have been confounded by phonological neighborhood density effects. Children might have been more sensitive to phoneme units in words that have many similar sounding neighbors in the vocabulary children are familiar with (i.e., high-frequency words), and less sensitive to phoneme units in words that have few similar sounding neighbors in the vocabulary children are familiar with. Effects that support the assumption about the connection between phonological neighborhood density and phonological development have been reported for rime oddity decisions (De Cara \& Goswami, 2003) and are, thus, likely to affect rime judgment decisions as well. Therefore, if words from sparse phonological neighborhoods are used, it is more likely to underestimate children's phonological development and, thus, find evidence for coarse-grained phonological processing. Therefore, phonological neighborhood density should be controlled in studies on rime awareness.

Third, in previous studies (Cardoso-Martins, 1994; Carroll \& Snowling, 2001; Wagensveld et al., 2012, 2013) the rime judgment tasks only included one distractor condition. Thus, these studies were not able to investigate whether participants distinguished between different (grain) sizes of phonological overlap. Based on the psycholinguistic grain size theory (Ziegler \& Goswami, 2005), it would be expected that preliterate children would be more sensitive to larger sizes of phonological overlap and less sensitive to smaller sizes of phonological overlap.

\section{The current study}

This study aimed to investigate whether the underlying phonological processing abilities of rime judgment decisions change as a function of literacy development. To this end, a new rime judgment task was developed that allowed us to study 
whether phonological similarity biases vary as a function of phonological overlap in different groups of participants. In a longitudinal study, the task was administered to a group of German-speaking children, two times before and two times after school entry, and a group of adults. Before school entry, children in Germany typically receive very little literacy stimulation (Kuger et al., 2013). In previous studies, no letter knowledge or reading abilities have been observed before school entry (Goswami et al., 2005; Mann \& Wimmer, 2002).

The rime judgment task included a rime (i.e., /t-arrl/ - /z:ar $1 /$ ) condition, a control condition (i.e., /t·ar $1 / /$ - /b·e: $\mathrm{t} /$ ), and two distractor conditions that varied in the size of phonological overlap with the target. In the body condition (i.e., /t:arr $1 / /$ - /t:aI ç/), the size of phonological overlap was the same as in the rime condition. In the nucleus condition (i.e., $/ \mathrm{t} \cdot \mathrm{ar} \cdot \mathrm{l} / \mathrm{-} / \mathrm{r} \cdot \mathbf{a r} \cdot \mathrm{s} /$ ), the phonological overlap was limited to one phoneme. Stimuli were controlled for phonological neighborhood density. Both accuracy and latency were recorded.

In line with the findings of Wagensveld et al. $(2012,2013)$, we expected that both children and adults would show phonological similarity effects. However, we also assumed that children before school entry primarily use larger units for phonological processing and, as a consequence, would show stronger similarity effects in the body than in the nucleus condition. After children had entered school and acquired first reading skills, they should also become sensitive to smaller grain sizes. We therefore expected to see no differences between the two conditions at later measurement points (and in adults).

\section{Method}

\section{Participants}

Data reported in this study are part of the longitudinal project PLAiT (Prerequisite Language Abilities in the Transitional phase).

\section{Adults}

The adult participants were 21 German-speaking students (10 male), recruited from three universities in Berlin. Their mean age was $24.85(S D=2.77)$ years and their reading abilities (as assessed with the Reading and Spelling Test; Moll \& Landerl, 2010) did not significantly differ from the population mean, $M=50.10$, $S D=23.47, t(20, \mu=50)<1$.

\section{Children}

Initially, 104 children were recruited from seven cooperating Early Childhood Education and Care institutions in Berlin. The children were only able to participate with the consent of their parents. Results are presented from a task, which was administered 10 months (T1) and 4 months (T2) before school entry, and 2 months (T3) and 10 months (T4) after school entry.

From the initial sample, 65 children provided complete data for all assessments. Four children were excluded from analysis because their parents reported that German was not their native language. The remaining 61 children (34 boys) 
were from middle to high socioeconomic backgrounds (HISEI: $M=67.67$; $S D=11.57$; HISEI $=$ highest value of the International Socio-Economic Index of Occupational Status; Ganzeboom, 2010; Ganzeboom, De Graaf, \& Treiman, 1992). Scores in standardized nonverbal intelligence (BUEVA-III; Esser \& Wyschkon, 2016), vocabulary (Kauschke \& Siegmüller, 2010), and phonological working memory (BUEVA; Esser \& Wyschkon, 2002) assessments indicated that children's general cognitive and language abilities were typically developed. The participating children were not able to read before school entry, which was indicated by the assessment of reading 2 months after school entry with a speeded, standardized word reading task (WLLP-R; Schneider, Blanke, Faust, \& Küspert, 2011). At this time, $34 \%$ of children were not able to identify a single word and variability in correct responses was large, $M=12.64, S D=10.24$. Ten months after school entry, the mean number of correctly identified words in $5 \mathrm{~min}$ had increased substantially, $M=37.03, S D=17.64$.

Children's mean age was 5 years, 4 months ( $5 ; 4 ; S D=3.12$ months) at T1, $5 ; 10$ $(S D=3.13$ months $)$ at $\mathrm{T} 2,6 ; 4(S D=3.15$ months $)$ at $\mathrm{T} 3$, and $7 ; 1 \quad(S D=3.13$ months) at T4. Before school entry, children were tested in individual sessions in a quiet room at the Early Childhood Education and Care institutions the child attended. After school entry, children were tested in quiet rooms at our research institute $(82 \%)$, at their school (13\%), or at their home (5\%). Children received a small toy for their participation.

\section{Rime judgment task}

The rime judgment task was a computerized task, presented using Inquisit (Version 3.1.0.6) with a DELL Latitude 520 laptop computer. Participants were instructed to listen to two words and decide whether the two words rimed. The words were presented with a pause of $500 \mathrm{~ms}$ between presentations. Participants could only answer after having heard both words completely. They indicated their answer by pressing a green key if the words rimed and a red key if the words did not rime. Four practice trials and 32 test trials were presented in randomized order. All participants were allowed to ask questions during the practice trials, and we verified that they had understood the task correctly before proceeding. Both response accuracy and latency were recorded.

\section{Design}

Children were asked to judge whether two monosyllabic nouns rimed or not. In each trial, children first heard a reference word (i.e., Teil, /t-ar $1 /$ ) followed by a second word that was varied based on the four different types of phonological overlap (Table 1). In the rime condition, the rime of both words overlapped (i.e., Seil, / z:ar.l/). In the body condition, the body of the words (i.e., onset and nucleus) overlapped (i.e., Teich, /taI ç/). In the nucleus condition, the vowel (nucleus) overlapped (i.e., Reis, $/ \mathrm{r} \cdot \mathrm{ar} \cdot \mathrm{s} /$ ), and in the control condition, there was no overlap between the two words (i.e., Beet, /b·e:t). 


\section{Materials}

Overall, 160 words were selected from a database for child-directed literature (childLex; Schroeder, Würzner, Heister, \& Kliegl, 2015). In line with the previous literature (Cardoso-Martins, 1994; Carroll \& Snowling, 2001), we used real words not pseudowords in our analysis. Wagensveld et al. (2013) had used both words and pseudowords in their analysis, but no relevant differences were found between the two groups. Furthermore, we were concerned that the young children would not be familiar with pseudoword stimuli, and thus, we would tap into other cognitive processes.

All words used in the study were high-frequent words (lemma frequency) from dense phonological neighborhoods (Coltheart neighbors). To ensure children's familiarity with the words, the familiarity was rated by 12 parents, who had children in a similar age as the participating children at $\mathrm{T} 1(M=5 ; 2 ; S D=9.66$ months $)$, in a pilot study. Parents rated each word that was used in the rime judgment task on a scale from 0 to 2 , with 0 representing no knowledge, 1 representing passive knowledge ("understands but doesn't use the word") and 2 representing regular production of the word ("understands and uses the word"). The average score of $M=1.77$ $(S D=0.57)$ indicated that children of the youngest age group being looked at in the study were on average familiar with the selected words.

Differences between types of overlap were controlled based on the Levenshtein distance between the conditions. Rime and body conditions did not differ significantly in Levenshtein distance, $t \leq 1, p>.05$, but both differed significantly from the control and nucleus condition, all $t s>2$, $p s<.001$. Nucleus and control condition also differed significantly in Levenshtein Distance, $t>2, p<.001$. Conditions were matched for word frequency, phonological neighborhood density, and number of phonemes, all $F s(3,124)<1$, all $p s>.05$. Table 1 summarizes mean Levenshtein distance, frequency, phonological neighborhood density, and number of phonemes for each condition and the reference words. Phonological complexity was diverse with $46 \%$ of words having a consonant-vowel-vowel-consonant (CVVC) or CVC, $23 \%$ a CVCC, $20 \%$ a CCVC or CCVVC structure, and $11 \%$ having other structures (CCVCC, CCVVCC, CVCCC, CVV, VCC, VCCC, VVCC, or VVCCC). However, analysis of variance analyses for group differences showed that there were no differences in conditions with regard to onset, $F(3,124)=0.32$, $p>.05$, vowel, $F(3,124)=1.12, p>.05$, and offset complexity, $F$ s $(3,124)=0.82$, $p>.05$ (see Table 1). German has more phonologically complex monosyllabic words than English (Marian et al., 2012), and complex words are, thus, representational for the words that German children grow up with and in which context phonological sensitivity develops (see also Wimmer et al., 1994, for other examples of similar item restrictions).

Four lists were created in which the target word was paired with one of the experimental conditions using a Latin square design. The lists were matched for Levenshtein distance, frequency, phonological neighborhood density, and number of phonemes, all $F s(3,124)<1$, all $p s<.05$. At each measurement point, children were assigned to a different list using a Latin square design.

The internal consistency of the task was measured for children and adults separately. For children, internal consistency was measured across all time points and 
Table 1. Item characteristics of words used in the rime judgment task

\begin{tabular}{|c|c|c|c|c|c|c|c|c|c|}
\hline & Example & IPA & $\begin{array}{l}\text { Levenshtein } \\
\text { distance }^{\mathrm{a}}\end{array}$ & $\begin{array}{l}\text { Word } \\
\text { frequency }^{b}\end{array}$ & $\begin{array}{l}\text { Phon. } \\
\text { neighbors }^{c}\end{array}$ & $\begin{array}{l}\text { Number of } \\
\text { phonemes }\end{array}$ & $\begin{array}{l}\text { Onset } \\
\text { complexity }^{d}\end{array}$ & $\begin{array}{c}\text { Vowel } \\
\text { complexitye }\end{array}$ & $\begin{array}{c}\text { Coda } \\
\text { complexity }\end{array}$ \\
\hline Reference & Tisch (table) & $/ \mathrm{t} \cdot \mathrm{I} \cdot \mathrm{S} /$ & - & 1.9 & 8.7 & 3.5 & 1.2 & 1.3 & 1.3 \\
\hline Nucleus & Blick (gaze) & /b-l.rk/ & 2.7 & 1.5 & 8.1 & 3.7 & 1.3 & 1.3 & 1.4 \\
\hline Rime & Fisch (fish) & $/ f \cdot \cdot \cdot \int /$ & 1.4 & 1.7 & 9.5 & 3.5 & 1.3 & 1.4 & 1.3 \\
\hline
\end{tabular}

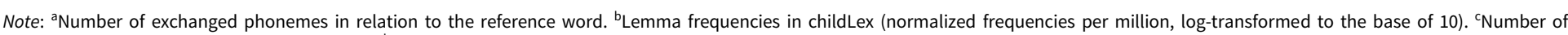
phonological Coltheart neighbors in childLex. ${ }^{d}$ Number of consonants. ${ }^{e}$ Vowel length represented by $1=$ short vowel and $2=$ long vowel. 
was good with Cronbach's $\alpha=0.82$. The same was true for adults with Cronbach's $\alpha=0.85$.

\section{Covariates}

To control for effects of task complexity in children, phonological working memory was assessed 10 months before school entry using a standardized digit recall task (BUEVA; Esser \& Wyschkon, 2002). The reliability of the task (Cronbach's $\alpha$ ) was good $(\alpha=0.80)$ and children scored in a range that is typical for this age, $M=20.75, S D=4.61$.

\section{Results}

In order to include both participant and item effects (generalized) linear mixed-effects models (Baayen, Davidson, \& Bates, 2008) were used for analysis using the $\{\operatorname{lme} 4\}$ package (Version 1.1-12) in R. A binomial model using a logit link was used for response accuracy, and a linear model was used for log-transformed response latencies. Only accurate responses were included in the response latency analysis. In addition, we excluded responses below $300 \mathrm{~ms}$ and responses longer than $10,000 \mathrm{~ms}$ (children) and 4,000 ms (adults). In addition, latencies that deviated more than $2.5 S D$ from the log-transformed participant or item mean were also discarded. Overall, $14.1 \%$ of children's responses (T1-T4) and $2.4 \%$ of adult's responses were excluded.

In all models, intercepts for participants and items were included as crossed random effects and type of overlap (4: rime, body, nucleus, or control) as a fixed effect. In the model for children, the factor time (4: T1, T2, T3, or T4) and its interaction with type of overlap was additionally included in the analysis. Furthermore, the continuous variable phonological working memory was included as a fixed effect in the analysis with children. Omnibus effects were calculated based on Type III model comparisons (using the Anova function in the R package $\{c a r\}$; Fox \& Weisberg, 2011). Post hoc analyses were carried out using single-degree-of-freedom contrasts based on the cell mean estimates in separate models with the same parameters. In order to avoid any misinterpretation due to a general affirmation bias (HeatherFritzley \& Lee, 2003), effects for affirmative responses (rime condition) and rejecting responses (control, body, and nucleus condition) were computed separately. In particular, the bias effects that are crucial for the present study (similarity and grain size) are defined as the difference between the control and the body or the nucleus condition and only involve rejecting responses. Descriptive results are provided in Table 2. The results of the mixed-effects model analysis for children are provided in Table 3 and reported within the text for adults.

\section{Children}

Accuracy

At the first time point, children's responses were above chance level in all conditions, all $t$ s $>10$, all $p$ s $<.001$, indicating that the children understood the task. The main effect of time was significant and indicated that children's performance 
Table 2. Descriptive statistics for response accuracy (\%) and latency (ms)

\begin{tabular}{|c|c|c|c|c|c|c|c|c|c|c|}
\hline & \multicolumn{5}{|c|}{ Accuracy } & \multicolumn{5}{|c|}{ Latency } \\
\hline & $\mathrm{T} 1$ & $\mathrm{~T} 2$ & T3 & $\mathrm{T} 4$ & Adults & $\mathrm{T} 1$ & $\mathrm{~T} 2$ & T3 & $\mathrm{T} 4$ & Adults \\
\hline Rime & $\begin{array}{l}95.07 \\
(1.04)\end{array}$ & $\begin{array}{l}91.98 \\
(1.51)\end{array}$ & $\begin{array}{l}93.20 \\
(1.15)\end{array}$ & $\begin{array}{l}96.39 \\
(0.82)\end{array}$ & $\begin{array}{l}95.37 \\
(1.60)\end{array}$ & $\begin{array}{c}2252 \\
(75)\end{array}$ & $\begin{array}{c}1759 \\
(59)\end{array}$ & $\begin{array}{c}1510 \\
(51)\end{array}$ & $\begin{array}{c}1490 \\
(50)\end{array}$ & $\begin{array}{l}254 \\
(22)\end{array}$ \\
\hline Body & $\begin{array}{l}71.45 \\
(3.89)\end{array}$ & $\begin{array}{l}84.60 \\
(2.54)\end{array}$ & $\begin{array}{l}89.27 \\
(1.92)\end{array}$ & $\begin{array}{l}95.56 \\
(0.97)\end{array}$ & $\begin{array}{l}98.21 \\
(1.02)\end{array}$ & $\begin{array}{c}2772 \\
(98)\end{array}$ & $\begin{array}{c}2194 \\
(76)\end{array}$ & $\begin{array}{c}1920 \\
(66)\end{array}$ & $\begin{array}{c}1854 \\
(63)\end{array}$ & $\begin{array}{l}338 \\
(29)\end{array}$ \\
\hline Nucleus & $\begin{array}{l}85.68 \\
(2.47)\end{array}$ & $\begin{array}{l}91.48 \\
(1.64)\end{array}$ & $\begin{array}{l}93.20 \\
(1.37)\end{array}$ & $\begin{array}{l}95.27 \\
(1.02)\end{array}$ & $\begin{array}{l}97.55 \\
(1.21)\end{array}$ & $\begin{array}{c}2482 \\
(86)\end{array}$ & $\begin{array}{c}2000 \\
(69)\end{array}$ & $\begin{array}{c}1706 \\
(58)\end{array}$ & $\begin{array}{c}1732 \\
(59)\end{array}$ & $\begin{array}{l}308 \\
(27)\end{array}$ \\
\hline Control & $\begin{array}{l}96.86 \\
(0.76)\end{array}$ & $\begin{array}{l}97.91 \\
(0.55)\end{array}$ & $\begin{array}{l}99.15 \\
(0.30)\end{array}$ & $\begin{array}{l}99.53 \\
(0.20)\end{array}$ & $\begin{array}{l}99.40 \\
(0.60)\end{array}$ & $\begin{array}{c}2278 \\
(76)\end{array}$ & $\begin{array}{c}1773 \\
(59)\end{array}$ & $\begin{array}{c}1578 \\
(53)\end{array}$ & $\begin{array}{c}1562 \\
(52)\end{array}$ & $\begin{array}{l}254 \\
(19)\end{array}$ \\
\hline
\end{tabular}

Note: Standard errors are provided in parentheses.

Table 3. Omnibus effects in the analysis of the rime judgment task

\begin{tabular}{|c|c|c|c|c|}
\hline \multirow[b]{2}{*}{ Effect } & \multicolumn{2}{|c|}{ Accuracy } & \multicolumn{2}{|c|}{ Latency (log) } \\
\hline & $\chi^{2}(d f)$ & $p$ & $F\left(d f, d f_{r e s}\right)$ & $p$ \\
\hline Intercept & $467.36(1)$ & $<.001$ & $77,963(1,65)$ & $<.001$ \\
\hline Phonological workingmemory & $4.39(1)$ & $<.05$ & $2.14(1,58)$ & $>.05$ \\
\hline Time & $76.59(3)$ & $<.001$ & $434.37(3,6594)$ & $<.001$ \\
\hline Type of overlap & $74.79(3)$ & $<.001$ & $45.53(3,125)$ & $<.001$ \\
\hline Time $\times$ Type of Overlap & $40.80(9)$ & $<.001$ & $0.7(9,6584)$ & $>.05$ \\
\hline
\end{tabular}

Note: Chi-square (accuracy) and $F$ values (latency) for effects using Type III sum of squares.

increased significantly across measurement points: children improved significantly from $\mathrm{T} 1, M=87.27 \%, S E=2.04$, to $\mathrm{T} 2, M=91.49 \%, S E=1.56, \Delta=4.22 \%, t>2$, $p<.01$; from T2 to T3, $M=94.01 \%, S E=1.19, \Delta=2.52 \%, t>3, p<.001$; and from T3 to T4, $M=96.69 \%, S E=0.75, \Delta=2.68 \%, t>3, p<.001$.

The main effect of type of overlap was also significant: as expected, responses in the rime condition were very accurate $(M>90 \%)$. More important, children's performance was lower in the body, $M=85.22 \%, S E=2.33$, and in the nucleus condition, $M=91.41 \%, S E=1.62$, than in the control condition, $M=98.36 \%$, $S E=0.45$, all $t s>6$, all $p s<.001$, indicating that children showed a phonological similarity effect in both conditions. In addition, performance in the body condition was significantly lower than in the nucleus condition, $t>2, p<.05$, indicating that the size of overlap affected the size of the similarity effect in children.

Furthermore, results showed a significant interaction of time and type of overlap (see Figure 1a). This interaction was driven by the fact that the effect of type of overlap differed between measurement points, $\chi^{2}(3)=16.60, p>.01$. More specifically, from $\mathrm{T} 1$ to $\mathrm{T} 3$, body and nucleus conditions differed significantly from each other, all $t \mathrm{~s}>1.7$, all $p \mathrm{~s}<.05$, while this difference was not significant at $\mathrm{T} 4, t<0.3$, $p>.05$. This effect, however, might be caused by ceiling effects in response accuracy and should therefore not be interpreted in isolation. 

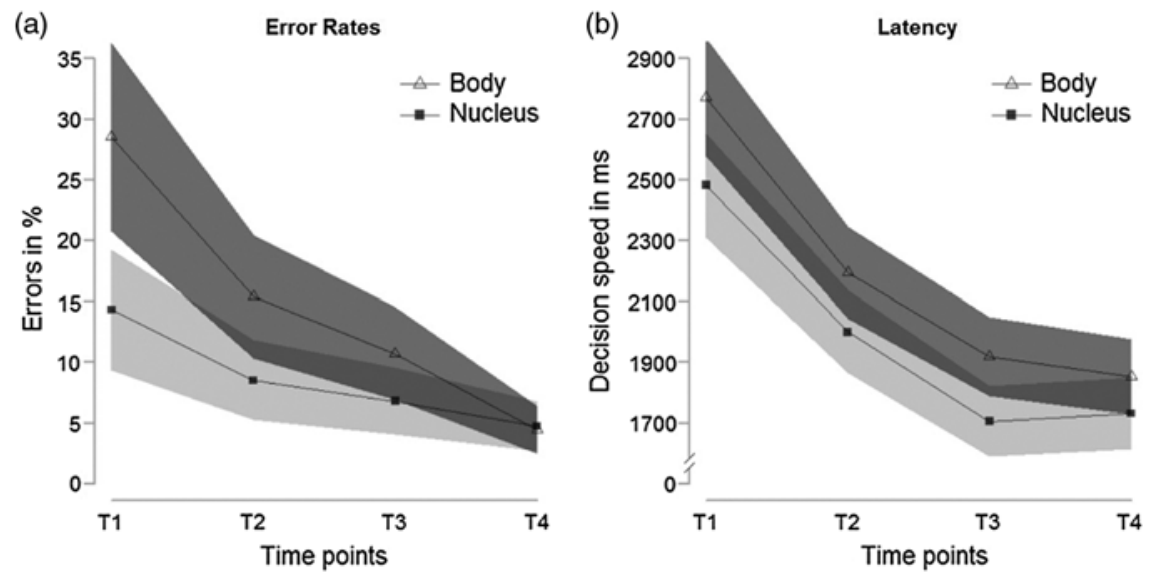

Figure 1. Trajectory of children's rime decision in body and nucleus conditions: (a) error rates and (b) latency. Depicted are means surrounded by areas representing standard errors.

\section{Response latency}

The main effect of time was significant, indicating that children improved significantly across all measurement points: children's responses became faster from T1, $M=2446$ $\mathrm{ms}, S E=84$, to T2, $M=1932, S E=66, \Delta=514 \mathrm{~ms}, t>17, p<.001$, and from T2 to T3, $M=1679, S E=57, \Delta=253 \mathrm{~ms}, t>8, p<.001$. From T3 to T4, $M=1660$, $S E=56$; however, the effect was not significant, $\Delta=119 \mathrm{~ms}, t<1.5, p>.05$.

In addition, the main effect of type of overlap was also significant (see Figure 1b): children were faster in the control condition, $M=1798 \mathrm{~ms}, S E=60$, than in both body, $M=2185 \mathrm{~ms}, S E=76$, and in the nucleus, $M=1980, S E=68$, condition, both $t$ s $>3.5$, $p$ s $<.001$, indicating that children showed phonological similarity biases in both conditions. However, children were also significantly slower in the body than the nucleus condition, $\Delta=205 \mathrm{~ms}: t>4, p<.001$, indicating that they were sensitive to the size of phonological overlap. Finally, children's responses in the rime condition were similarly fast as in the control condition, $t<2, p>.05$.

\section{Adults}

In accuracy responses, adult participants were at ceiling in all conditions and the effect of type of overlap was not significant, $\chi^{2}(3)=0.19, p>.05$. In latency responses, by contrast, the main effect of type of overlap was significant, $F(3$, $118)=9.61, p<.001$. Responses were faster in the control condition than in both body and nucleus conditions (see descriptive statistics in Table 2); both $t$ s $>2$, $p s<.001$. This indicated that adults showed phonological similarity biases in both conditions. In contrast to children, however, responses in the body and the nucleus conditions did not differ significantly from each other: $t<1.3, p>.05$.

\section{Joined analysis of adults and children}

In order to compare children and adults directly with each other and test explicitly where and how effects change during reading development, we conducted a 
Table 4. Descriptive statistics for $z$-standardized response latencies

\begin{tabular}{|c|c|c|c|c|c|}
\hline & $\mathrm{T} 1$ & $\mathrm{~T} 2$ & T3 & $\mathrm{T} 4$ & Adults \\
\hline Rime & $\begin{array}{l}-0.18 \\
(0.05)\end{array}$ & $\begin{array}{l}-0.23 \\
(0.04)\end{array}$ & $\begin{array}{l}-0.26 \\
(0.04)\end{array}$ & $\begin{array}{l}-0.25 \\
(0.04)\end{array}$ & $\begin{array}{l}-0.10 \\
(0.08)\end{array}$ \\
\hline Body & $\begin{array}{c}0.44 \\
(0.06)\end{array}$ & $\begin{array}{c}0.40 \\
(0.06)\end{array}$ & $\begin{array}{c}0.43 \\
(0.05)\end{array}$ & $\begin{array}{c}0.30 \\
(0.05)\end{array}$ & $\begin{array}{c}0.24 \\
(0.08)\end{array}$ \\
\hline Nucleus & $\begin{array}{c}0.03 \\
(0.05)\end{array}$ & $\begin{array}{c}0.09 \\
(0.04)\end{array}$ & $\begin{array}{c}0.02 \\
(0.04)\end{array}$ & $\begin{array}{c}0.10 \\
(0.05)\end{array}$ & $\begin{array}{c}0.07 \\
(0.07)\end{array}$ \\
\hline Control & $\begin{array}{l}-0.16 \\
(0.04)\end{array}$ & $\begin{array}{l}-0.18 \\
(0.04)\end{array}$ & $\begin{array}{l}-0.13 \\
(0.04)\end{array}$ & $\begin{array}{l}-0.14 \\
(0.04)\end{array}$ & $\begin{array}{l}-0.22 \\
(0.07)\end{array}$ \\
\hline
\end{tabular}

Note: $Z$ standardization by participant.

combined analysis using by participant $z$-transformed response latencies to control for over-additivity effects (Faust, Balota, Spieler, \& Ferraro, 1999). Descriptive statistics of $z$-transformed response latencies are provided in Table 4.

In order to quantify the size of both phonological similarity effects (body and nucleus vs. control) as well as the effect of grain size use (body vs. nucleus) we set up customized, single degree of freedom contrasts. Results across both groups show a main effect for the phonological similarity effects, $F(1,135)=15.31$, $p<.001$, and for the effect of grain size use, $F(1,135)=62.39, p<.001$. Furthermore, both effects developed significantly over time, which was indicated by a Phonological Similarity $\times$ Time Interaction effect, $F(5,1,303)=5.19, p<.001$, and a Grain Size $\times$ Time interaction effect, $F(5,1,289)=14.16, p<.001$. In the following, results of post hoc analyses that were carried out using single degree of freedom contrasts based on the cell mean estimates are reported. Presented results include replications of the results above and additionally direct comparisons of the effects in children and adults.

\section{Phonological similarity effects}

Children showed a significant phonological similarity effects at T1, $t=6.7, p<.001$, $\mathrm{T} 2, t=7.27, p<.001$, T3, $t=6.46, p<.001$, and T4, $t=6.46, p<.001$, and adults showed a phonological similarity effect as well, $t=3.68, p<.001$. However, effect sizes decreased across time, T1: $\beta=0.9, S E=0.14$; T2: $\beta=1.0, S E=0.13$; T3: $\beta=0.85, S E=0.13$; T4: $\beta=0.85, S E=0.13$; adults: $\beta=0.65, S E=0.18$. The interaction effect was explained by significant differences between effects at T1 and T2 (before school entry) compared with the phonological similarity effect in adults, $t=1.7$, all $p<.05$, while the same effect at T3 and T4 (after school entry) did not differ significantly from the effect in adults, $t<1.2, p>.05$.

\section{Grain size effect}

As reported above, there was a significant grain size effect in children at all time points, all $t \mathrm{~s}>2$, all $p s>.05$, but no significant grain size effect in adults, $t<1.4, p>.05$. However, effect sizes decreased strongly across development with the largest drop throughout the first school year, T1: $\beta=0.42, S E=0.10$; T2: 
$\beta=0.31, S E=0.09 ;$ T3: $\beta=0.40, S E=0.09 ; \quad \mathrm{T} 4: \quad \beta=0.20, \quad S E=0.09 ;$ adults: $\beta=0.17, S E=0.12$. Thus, the interaction effect was due to a significant decrease in effects from T1/T2 to T3/T4, $t=2.26, p<.05$. Furthermore, effects between children at the end of first grade and adults did not differ significantly from each other, $t=0.19, p>.05$.

\section{Discussion}

In this longitudinal study, a rime judgment task was administered to a group of German-speaking children two times before and two times after school entry as well as to a group of adults. Participants were asked to judge whether a target word rimed with a reference word or not. The target words overlapped with the reference word

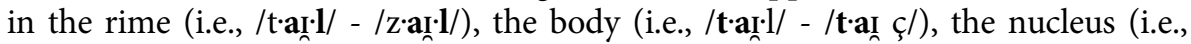
$/ \mathrm{t} \cdot \mathrm{ar} \cdot \mathrm{l} / \mathrm{-}-/ \mathrm{r} \cdot \mathbf{a r} \cdot \mathrm{s} /$ ), or not at all (control condition; i.e., $/ \mathrm{t} \cdot \mathrm{r} \cdot \mathrm{S} / \mathrm{-} / \mathrm{b} \cdot \mathrm{e} \cdot \mathrm{t} / \mathrm{t})$. The question in focus was whether participants showed phonological similarity effects, that is, are distracted by the phonological overlap in the distractor conditions relative to the control condition. In contrast to previous studies, we manipulated the size of the phonological overlap in the distractor conditions. In line with the assumptions of the psycholinguistic grain size theory about phonological development in German (Ziegler \& Goswami, 2005), we expected that the size of the similarity effect will differ between distractor conditions before children start to learn to read, because they are more likely to use larger grain sizes for phonological processing. Children who have already acquired some reading skills (and adults), by contrast, should also be able to process words using smaller grain sizes and, as a consequence, show the same similarity effect in both distractor conditions.

\section{Effects of phonological similarity across development}

In line with our expectations, children and adults showed strong similarity effects; that is, both groups consistently misjudged nonrhyming word pairs significantly more often as rhyming, if they had some phonological overlap with the target word. Children showed this effect at all measurement points in both response accuracy and latency. In adults, this effect was only observed in response latency, because accuracy rates showed strong ceiling effects. This finding replicates the results of previous studies that found similarity biases in preliterate children (CardosoMartins, 1994; Carroll \& Snowling, 2001). In addition, and similar to Wagensveld et al. (2012, 2013), we found that phonological similarity effects were also present in children after they had acquired first reading skills and in adults. The analysis of byparticipant $z$-transformed response latencies, furthermore, showed that the size of this effect decreased significantly throughout development. On the one hand, this supports the assumption that phonological overlap affects responses on rime judgment tasks in general and that this bias is stable across reading development. On the other hand, this also indicates that phonological similarity effects decrease with the onset of reading acquisition. 


\section{Grain size effects in phonological processing during rime judgment}

In addition, we found that the phonological similarity biases were affected by the size of overlap between the reference and the target word and that this effect evolved with reading development. Specifically, in accuracy responses, children showed a stronger similarity bias effect in the body condition than in the nucleus condition before and shortly after school entry but not at the end of first grade, when first fluent reading abilities had been acquired. However, this could also be explained by ceiling effects, and furthermore, results could not be compared to adults, who were at ceiling in accuracy responses. This is why we also analyzed the response latencies in both children and adults.

Response latency analysis showed that children were more sensitive and, as a consequence, slower in the body condition compared to the nucleus condition. The same effect was, however, not found in adults. A joined response latency analysis of children and adults with $z$-transformed data revealed a significant interaction of the grain size effect (body vs. nucleus) with time. This interaction was explained by a decreasing size of effect in children with effects being stronger before school entry and at the beginning of first grade $(\sim 0.3-0.4)$ and decreasing throughout the first year of reading instruction $(\sim 0.2)$. The rather small effect of differences in phonological processing with regard to grain size did not differ between children at the end of first grade and adults. Thus, children were more sensitive to larger than smaller grain sizes before they had learned to read and gradually developed an additional sensitivity for smaller grain sizes with literacy development.

\section{Conclusions}

Our findings suggest that phonological processing is affected by literacy development and develops from more coarse-grained (or holistic) to more fine-grained (or analytical) processing as a function of reading acquisition. This is in line with the psycholinguistic grain size theory (Ziegler \& Goswami, 2005), which assumes that preliterate children are more sensitive to larger phonological grain sizes and are only able to process smaller grain sizes after having acquired some reading skills. However, the observation by Ziegler and Goswami (2005) was mainly based on the results of phoneme awareness tasks (e.g., letter substitution). Our results demonstrate that this finding also generalizes to rime judgment and, presumably, other phonological tasks that involve similarity judgments. This is particularly important in educational environments, in which phoneme awareness is not explicitly taught before school entry, and thus, phoneme awareness is difficult to assess at early points in development (Castles \& Coltheart, 2004).

It is important to note that the present findings have been found in Germanspeaking children. German has a transparent orthography (Schmalz, Marinus, Coltheart, \& Castles, 2015; Seymour, Aro, \& Erskine, 2003), and studies have shown that children in transparent orthographies adopt a phoneme-based decoding strategy earlier than children in opaque orthographies and achieve first automatized reading strategies within the first year of instruction (Goswami et al., 2005). It can be expected that the developmental onset of this effect varies as a function of orthographic transparency and that children learning to read in an opaque 
orthography (e.g., English) would still show effects at the end of first grade that are more similar to the effects for preliterate children in the present study.

\section{Limitations and directions for future studies}

In this study we used a highly controlled item set that was also controlled for dense phonological neighborhood density. German is a language with few phonological neighbors, if compared, for example, to English or French (Marian et al., 2012). Differences in phonological processing between words from sparse and dense phonological neighborhoods have already been found in rime awareness tasks in English (Hogan, Bowles, Catts, \& Storkel, 2011) and, given the phonological language structure, are likely to be found in German as well. Thus, studies on the development of rime awareness with words from both sparse and dense phonological neighborhoods in German or languages with similar phonological structures would be helpful to increase the understanding of phonological development.

There are also some methodological problems that we were not able to address in the present study. For example, it would be interesting to also include other phonological overlap conditions that vary large phonological overlap by position or phonetic quality (i.e., /t·ar $\mathbf{l} / \mathbf{l}-/ \mathbf{t} \cdot \mathbf{a}: \mathbf{l} /$; nucleus substitution). This is also important for theory, because one of the assumptions of the psycholinguistic grain size theory is that phonological sensitivity progresses from syllables to onset-rime awareness to phonemes, which makes this progression dependent on the position of phonemes in a word. This assumption is mainly based on findings from English (i.e., Kirtley, Bryant, MacLean, \& Bradley, 1989). However, Geudens and Sandra (2003) were able to negate the assumption that young children are particularly sensitive to onset-rime structure for Dutch, which is not only phonologically but also in general language structure more closely related to German than English. However, there are very few direct neighbors in German (Marian et al., 2012). Thus, we were not able to find enough words with other overlaps that would have met the criteria of this study and would have been familiar to young children. It would, however, be interesting to include conditions with varying overlap with regard to phoneme position and phonetic quality in future studies.

Finally, the same is true for the inclusion of more small overlap conditions to contrast effects of consonant overlap with vowel overlap (nucleus; i.e., /t:ar.l/ /t:e:r/). Again, we had difficulties finding suitable words for young children that would meet the rest of our criteria, and furthermore, we would have increased an already large item set for a group of young participants with, thus, a limited attention span. Therefore, we decided to use an additive pattern instead (vowel vs. vowel + consonant) to ensure that differences in the conditions cannot be explained solely by vowel saliency. However, as we had no condition that tested only consonant overlap, we cannot rule out confounds caused by differences in processing of vowels and consonants completely. Adding a condition with only consonant overlap should, therefore, be considered in future studies. 


\section{Summary}

In sum, our results confirm that in German a phonological similarity bias is observed in preliterate and literate children as well as in adults. However, the strength of the effect is affected by the amount of overlap between reference and target word, and the size of this effect decreases in parallel to literacy development. Preliterate children are more sensitive to larger phonological processing units and, as a consequence, show stronger phonological similarity effects if the overlap between target and reference word is large. Literate children and adults, by contrasts, are also sensitive to small phonological processing units and their response behavior is, therefore, influenced less by the amount of phonological overlap. Thus, results support the claims of the psycholinguistic grain size theory (Ziegler \& Goswami, 2005). Results also show that not only development in phoneme awareness but also development in rime awareness is linked to literacy development.

Author ORCIDs. (1D) Sascha Schroeder, 0000-0001-7001-4588

Acknowledgments. We thank Julia Mann, Felix Klapproth, and Elisabeth Klose for their support in data collection.

\section{References}

Anthony, J. L., \& Francis, D. J. (2005). Development of phonological awareness. Current Directions in Psychological Science, 14, 255-259. doi: 10.1111/j.0963-7214.2005.00376.x

Anthony, J. L., \& Lonigan, C. J. (2004). The nature of phonological awareness: Converging evidence from four studies of preschool and early grade school children. Journal of Educational Psychology, 96, 43-55. doi: 10.1037/0022-0663.96.1.43

Baayen, R. H., Davidson, D. J., \& Bates, D. M. (2008). Mixed-effects modeling with crossed random effects for subjects and items. Journal of Memory and Language, 59, 390-412. doi: 10.1016/j.jml.2007.12.005

Bradley, L., \& Bryant, P. (1978). Difficulties in auditory organization as a possible cause of reading backwardness. Nature, 271, 746-748. doi: 10.1038/271746a0

Caravolas, M., Lervåg, A., Defior, S., Málková, G. S., \& Hulme, C. (2013). Different patterns, but equivalent predictors, of growth in reading in consistent and inconsistent orthographies. Psychological Science, 24, 1398-1407. doi: 10.1177/0956797612473122

Cardoso-Martins, C. (1994). Rime perception: Global or analytical? Journal of Experimental Child Psychology, 57, 26-41.

Carroll, J. M., \& Myers, J. M. (2011). Spoken word classification in children and adults. Journal of Speech, Language, and Hearing Research, 54, 127-147. doi: 10.1044/1092-4388(2010/08-0148

Carroll, J. M., \& Snowling, M. J. (2001). The effects of global similarity between stimuli on children's judgment of rime and alliteration. Applied Psycholinguistics, 22, 327-342.

Castles, A., \& Coltheart, M. (2004). Is there a causal link from phonological awareness to success in learning to read? Cognition, 91, 77-111. doi: 10.1016/S0010-0277(03)00164-1

De Cara, B., \& Goswami, U. (2003). Phonological neighbourhood density: Effects in a rime awareness task in five-year-old children. Journal of Child Language, 30, 695-710. doi: 10.1017/S0305000903005725

Ennemoser, M., Marx, P., Weber, J., \& Schneider, W. (2012). Spezifische Vorläuferfertigkeiten der Lesegeschwindigkeit, des Leseverständnisses und des Rechtschreibens. Zeitschrift für Entwicklungspsychologie und Pädagogische Psychologie, 44, 53-67. doi: 10.1026/0049-8637/a000057

Esser, G., \& Wyschkon, A. (2002). Basisdiagnostik für Umschriebene Entwicklungsstörungen im Vorschulalter: BUEVA. Göttingen: Beltz.

Esser, G., \& Wyschkon, A. (2016). Basisdiagnostik Umschriebener Entwicklungsstörungen im Vorschulalter -Version III (BUEVA-III). Göttingen: Hogrefe. 
Faust, M. E., Balota, D. A., Spieler, D. H., \& Ferraro, F. R. (1999). Individual differences in informationprocessing rate and amount: implications for group differences in response latency. Psychological bulletin, 125, 777-799.

Fox, J., \& Weisberg, S. (2011). An $\{R\}$ companion to applied regression (2nd ed.). Thousand Oaks, CA: Sage.

Ganzeboom, H. B. G. (2010). A new International Socio-Economic Index (ISEI) of occupational status for the International Standard Classification of Occupation 2008 (ISCO-08) constructed with data from the ISSP 2002-2007. Paper presented at the Annual Conference of International Social Survey Programme, Lisbon.

Ganzeboom, H. B.G., De Graaf, P. M., \& Treiman, D. J. (1992). A Standard International Socio-Economic Index of Occupational Status. Social Science Research, 21, 1-56. doi: 10.1016/0049-089X(92)90017-B

Geudens, A., \& Sandra, D. (2003). Beyond implicit phonological knowledge: No support for an onset-rime structure in children's explicit phonological awareness. Journal of Memory and Language, 49, 157-182. doi: 10.1016/S0749-596X(03)00036-6

Goswami, U. (1999). Causal connections in beginning reading: The importance of rime. Journal of Research in Reading, 22, 217-240. doi: 10.1111/1467-9817.00087

Goswami, U., \& Bryant, P. (1990). Phonological skills and learning to read. London: Psychology Press.

Goswami, U., \& de Cara, B. (2000). Lexical representations and development: The emergence of rime processing. Paper presented at the ISCA Tutorial and Research Workshop (ITRW) on Spoken Word Access Processes, Nijmegen, the Netherlands.

Goswami, U., Ziegler, J. C., Dalton, L., \& Schneider, W. (2001). Pseudohomophone effects and phonological recoding procedures in reading development in English and German. Journal of Memory and Language, 45, 648-664.

Goswami, U., Ziegler, J. C., \& Richardson, U. (2005). The effects of spelling consistency on phonological awareness: A comparison of English and German. Journal of Experimental Child Psychology, 92, 345-365. doi: $10.1016 /$ j.jecp.2005.06.002

Heather Fritzley, V., \& Lee, K. (2003). Do young children always say yes to yes-no questions? A metadevelopmental study of the affirmation bias. Child Development, 74, 1297-1313. doi: 10.1111/1467-8624. 00608

Hogan, T. P., Bowles, R. P., Catts, H. W., \& Storkel, H. L. (2011). The influence of neighborhood density and word frequency on phoneme awareness in 2nd and 4th grades. Journal of Communication Disorders, 44, 49-58. doi: 10.1016/j.jcomdis.2010.07.002

Inquisit (Version 3.1.0.6.) [Computer Software]. Seattle, WA: Millisecond Software.

Kauschke, C., \& Siegmüller, J. (2010). Patholinguistische Diagnostik bei Sprachentwicklungsstörungen (PDSS) (Vol. 4). München: Elsevier, Urban \& Fischer Verlag.

Kirtley, C., Bryant, P., MacLean, M., \& Bradley, L. (1989). Rhyme, rime, and the onset of reading. Journal of Experimental Child Psychology, 48, 224-245.

Kuger, S., Rossbach, H.-G., \& Weinert, S. (2013). Early literacy support in institutional settings-A comparison of quality of support at the classroom level and the individual child level. In M. Pfost, C. Artelt, and S. Weinert (Eds.), Schriften aus der Fakultät Humanwissenschaften der Otto-Friedrich-Universität Bamberg: Vol. 14. The Development of Reading Literacy from Early Childhood to Adolescence: Empirical findings from the Bamberg BiKS longitudinal studies (pp. 63-93). Bamberg: Universty of Bamberg Press.

Lonigan, C. J., Burgess, S. R., Anthony, J. L., \& Barker, T. A. (1998). Development of phonological sensitivity in 2- to 5-year-old children. Journal of Educational Psychology, 90, 294-311.

Luce, P. A., \& Pisoni, D. B. (1998). Recognizing spoken words: The neighborhood activation model. Ear and Hearing, 19, 1-36.

Macmillan, B. (2002). Rime and reading: A critical review of the research methodology. Journal of Research in Reading, 25, 4-42. doi: 10.1111/1467-9817.00156

Mann, V., \& Wimmer, H. (2002). Phoneme awareness and pathways into literacy: A comparison of German and American children. Reading and Writing, 15, 653-682. doi: 10.1023/A:1020984704781

Marian, V., Bartolotti, J., Chabal, S., \& Shook, A. (2012). CLEARPOND: Cross-linguistic easy access resource for phonological and orthographic neighborhood densities. PLOS ONE, 7, e43230. doi: 10. 1371/journal.pone.0043230

McBride-Chang, C., \& Kail, R. V. (2002). Cross-cultural similarities in the predictors of reading acquisition. Child Development, 73, 1392-1407. doi: 10.1111/1467-8624.00479 
McBride-Chang, C., \& Suk-Han Ho, C. (2005). Predictors of beginning reading in Chinese and English: A 2-year longitudinal study of Chinese kindergartners. Scientific Studies of Reading, 9, 117-144. doi: 10. 1207/s1532799xssr0902_2

Metsala, J. L., \& Walley, A. C. (1998). Spoken vocabulary growth and the segmental restructuring of lexical representations: Precursors to phonemic awareness and early reading ability. In J. L. Metsala, and L. C. Ehri (Eds.), Word recognition in beginning literacy (pp. 83-112). Mahwah, NJ: Erlbaum.

Moll, K., \& Landerl, K. (2010). Lese-und Rechtschreibtest (SLRT-II). In Weiterentwicklung des Salzburger Lese-und Rechtschreibtests (SLRT). (Reading and Spelling Test SLRT-II). Bern: Hans Huber.

Näslund, J. C., \& Schneider, W. (1996). Kindergarten letter knowledge, phonological skills, and memory processes: Relative effects on early literacy. Journal of Experimental Child Psychology, 62, 30-59. doi: 10. 1006/jecp.1996.0021

Schmalz, X., Marinus, E., Coltheart, M., \& Castles, A. (2015). Getting to the bottom of orthographic depth. Psychonomic Bulletin \& Review, 22, 1614-1629. doi: 10.3758/s13423-015-0835-2

Schneider, W., Blanke, I., Faust, V., \& Küspert, P. (2011). Würzburger Leise Leseprobe-Revision (WLLP-R). Ein Gruppentest für die Grundschule (Revidierte Version). Göttingen: Hogrefe Verlag.

Schroeder, S., Würzner, K. M., Heister, J., Geyken, A., \& Kliegl, R. (2015). childLex: A lexical database of German read by children. Behavioral Research, 47, 1085-1094. doi: 10.3758/s13428-014-0528-1

Seymour, P. H. K., Aro, M., \& Erskine, J. M. (2003). Foundation literacy acquisition in European orthographies. British Journal of Psychology, 94, 143-174. doi: 10.1348/000712603321661859

Wagensveld, B., Segers, E., van Alphen, P., \& Verhoeven, L. (2013). The role of lexical representations and phonological overlap in rime judgments of beginning, intermediate and advanced readers. Learning and Individual Differences, 23, 64-71. doi: 10.1016/j.lindif.2012.09.007

Wagensveld, B., van Alphen, P., Segers, E., \& Verhoeven, L. (2012). The nature of rime processing in preliterate children. British Journal of Educational Psychology, 82, 672-689. doi: 10.1111/j.2044-8279. 2011.02055.x

Walley, A. (1993). The role of vocabulary development in children's spoken word recognition and segmentation ability. Developmental Review, 13, 286-350. doi: 10.1006/drev.1993.1015

Wimmer, H., Landerl, K., \& Schneider, W. (1994). The role of rhyme awareness in learning to read a regular orthography. British Journal of Developmental Psychology, 12, 469-484. doi: 10.1111/j.2044835X.1994.tb00648.x

Ziegler, J. C., Bertrand, D., Tóth, D., Csépe, V., Reis, A., Faísca, L., \& Blomert, L. (2010). Orthographic depth and its impact on universal predictors of reading: A cross-language investigation. Psychological Science, 21, 551-559. doi: 10.1177/0956797610363406

Ziegler, J. C., \& Goswami, U. (2005). Reading acquisition, developmental dyslexia, and skilled reading across languages: A psycholinguistic grain size theory. Psychological Bulletin, 131, 3-29. doi: $10.1037 /$ 0033-2909.131.1.3

\section{Appendix A}

Table A.1. Stimuli of the rime judgment task

\begin{tabular}{|c|c|c|c|c|}
\hline Reference & Rime & Vowel & Body & Control \\
\hline Kopf & Topf & Gott & Korb & Fall \\
\hline Haus & Maus & Maul & Haupt & Chor \\
\hline Ball & Knall & Watt & Bar & Tier \\
\hline Tisch & Fisch & Blick & Tipp & Kalb \\
\hline Flur & Schnur & Blut & Flug & Sog \\
\hline Kloß & Moos & Boot & Chlor & Grab \\
\hline Fett & Bett & Speck & Fell & Saal \\
\hline
\end{tabular}


Table A.1. (Continued)

\begin{tabular}{|c|c|c|c|c|}
\hline Reference & Rime & Vowel & Body & Contro \\
\hline Mund & Hund & Furz & Mut & Tat \\
\hline Kind & Wind & Mist & Kinn & Dachs \\
\hline Bauch & Hauch & Traum & Baum & Wal \\
\hline Wurm & Turm & Sumpf & Wurst & Lied \\
\hline Bus & Nuss & Lust & Busch & Kraft \\
\hline Hut & Glut & Stuhl & Huf & Schal \\
\hline Buch & Tuch & Mus & Bug & Angst \\
\hline Ring & Ding & Witz & Riff & Brot \\
\hline Dill & Grill & Film & Ding & Band \\
\hline Bad & Rad & Mal & Bahn & Frosch \\
\hline Tank & Schrank & Rand & Tanz & Bild \\
\hline Stand & Wand & Gang & Stall & Glück \\
\hline Stock & Block & Zopf & Storch & $\mathrm{Biß}$ \\
\hline Stein & Bein & Beil & Steig & Keks \\
\hline Mann & Bann & Brand & Mark & Heft \\
\hline Sack & Lack & Quatsch & Saft & Spur \\
\hline Gras & Glas & Mars & Graf & Moor \\
\hline Schiff & Griff & Tritt & Schild & Arzt \\
\hline Halt & Wald & Gast & Hall & Frucht \\
\hline Kuh & Schuh & Wut & Kur & Leim \\
\hline Stamm & Kamm & Blatt & Stadt & Hirn \\
\hline Herd & Pferd & Werft & Herz & Docht \\
\hline Teil & Seil & Reis & Teich & Beet \\
\hline Art & Fahrt & Schaf & Arm & Huhn \\
\hline Dank & Bank & Bart & Dampf & Licht \\
\hline
\end{tabular}

Cite this article: Schmitterer AMA and Schroeder S (2019). Grain size effects in rime judgment across literacy development in German. Applied Psycholinguistics 40, 673-691. https://doi.org/10.1017/ S0142716418000784 